\title{
Eradication of Helicobacter pylori with clarithromycin and omeprazole
}

\author{
R P H Logan, P A Gummett, H D Schaufelberger, R R F H Greaves, G M Mendelson, \\ M M Walker, P H Thomas, J H Baron, J J Misiewicz
}

\begin{abstract}
Clarithromycin, a new and well tolerated, acid stable macrolide antibiotic, has a similar antimicrobial spectrum to erythromycin but a better in vitro $\mathrm{MIC}_{90}\left(0.03 \mu \mathrm{g} / \mathrm{I}^{-1}\right)$ against Helicobacter pylori (H pylori). This study aimed at determining the eradication rate using clarithromycin $500 \mathrm{mg}$ thrice daily and omeprazole $40 \mathrm{mg}$ daily for two weeks. Patients were given an endoscopy and $H$ pylori status assessed by antral culture (microaerobic conditions, for up to $\mathbf{1 0}$ days), antral and corpus histology tests (haematoxylin and eosin/ Gimenez stains), and ${ }^{13} \mathrm{C}$-urea breath test $\left({ }^{13} \mathrm{C}\right.$-UBT, European standard protocol, positive result $=$ excess $\delta^{13} \mathrm{CO}_{2}$ excretion $>5$ per mil). Compliance waa assessed by returned tablet counts. $H$ pylori clearance at the end of treatment and eradication four weeks after finishing treatment were assessed by the ${ }^{13}$ C-UBT. Seventy three patients (54 men, median age 45 years) with duodenal ulcers $(n=42)$ or duodenitis/non-ulcer dyspepsia $(n=31)$ all with a positive ${ }^{13} \mathrm{C}$-UBT (mean (SEM) excess $\delta^{-13} \mathrm{CO}_{2}$ excretion=26.6 (4.9) per mil) and either positive antral histology $(n=72)$ or positive antral culture $(n=35)$ were studied. Before treatment $2 / 27(7 \%)$ isolates of $H$ pylori were resistant to clarithromycin and five isolates were resistant to metronidazole. In $70 / 73(96 \%)$ the ${ }^{13} \mathrm{C}$-UBT was negative immediately after finishing treatment. Four weeks later the ${ }^{13} \mathrm{C}$-UBT was negative in $57 / 73$ (mean (SEM) excess $\delta^{13} \mathrm{CO}_{2}$ excretion $=1.2(0.3)$ per mil, eradication rate $=78 \%)$. Forty eight $(66 \%)$ patients experienced a metallic taste while taking the tablets. Although four (5\%) patients, however, could not complete the course of treatment, in only one of these four was $\boldsymbol{H}$ pylori not eradicated. These results show that duel therapy with clarithromycin and omeprazole is well tolerated. With an eradication rate of $78 \%$ it is an effective treatment for metronidazole resistant $H$ pylori and may be an alternative to standard triple therapy.
\end{abstract}

(Gut 1994; 35: 323-326)

Eradication of Helicobacter pylori ( $H$ pylori) cures gastritis and prevents relapse of duodenal ulcer. ${ }^{1}$ There are several drawbacks, however, to the recommended two week triple therapy for eradicating $H$ pylori. ${ }^{2}$ Bismuth salts, an important component of most regimens are not universally available, while failure of eradication therapy is often associated with pretreatment metronidazole resistant $H$ pylori. ${ }^{34}$ Poor compliance with treatment because of side effects, frequent dosing, and the length of treatment is also a factor. ${ }^{5}$ Simpler and better tolerated regimens that contain neither bismuth nor metronidazole are needed.

Omeprazole, a $\mathrm{H}^{+} / \mathrm{K}^{+}$ATPase inhibitor, has been proposed as a suitable adjunct to $H$ pylori treatment regimens for several reasons. It seems to suppress $H$ pylori directly ${ }^{6-8}$ and to increase the antibacterial effectivness of some antibiotics by increasing the gastric $\mathrm{pH}$ towards their negative logarithms of the acidic dissociation constant (pKa). Omeprazole may also decrease the acid storage pool for weak base antibiotics (thus increasing the gastric mucosal concentration) and may decrease the rate of intragastric catabolism of the antimicrobial.

Clarithromycin (Abbott Laboratories, North Chicago, Illinois) is a new macrolide antibiotic (6-methoxy-erythromycin) with similar antimicrobial spectrum to erythromycin, but is more acid stable with fewer alimentary side effects. It has more predictable pharmacokinetics and has a half life of eight hours. ${ }^{10}$ Clarithromycin is used for the treatment of upper and lower respiratory tract infections and at doses of $2 \mathrm{~g}$ twice daily has been shown to be effective in HIV positive patients with Mycobacterium avium complex infections. In vitro its $\mathrm{MIC}_{90}$ against $H$ pylori is $0.03 \mu \mathrm{g} \mathrm{ml}^{-1}$. To develop a regimen that contains neither bismuth, nor metronidazole, we have assessed the effectiveness of two weeks treatment with clarithromycin $500 \mathrm{mg}$ thrice daily and omeprazole $40 \mathrm{mg}$ in the morning in eradicating $H$ pylori.

\section{Patients and methods}

After routine diagnostic upper gastrointestinal endoscopy, patients with known $H$ pylori infection were invited to enter the study, which was approved by the Parkside ethical committee. The patients gave written informed consent. Patients with previous gastric surgery, known bleeding diathesis, penicillin allergy, or taking oral anticoagulants were excluded.

All endoscopes were disinfected after each examination using an automatic washing machine (Olympus EW20) and the biopsy forceps were sterilised by autoclaving. ${ }^{11}$

ASSESSMENT OF H PYLORI STATUS

$H$ pylori status was determined using the ${ }^{13} \mathrm{C}$-urea breath test $\left({ }^{13} \mathrm{C}\right.$-UBT, see over) and histological examination (two antral biopsy specimens processed to paraffin wax, haematoxylin and eosin and Gimenez stains). Whenever possible, after initial isolation (two antral and two corpus biopsy specimens, selective and 
non-selective media, microaerobic conditions for up to 10 days), pure cultures were harvested and stored in $10 \%$ glycerol broth at $-80^{\circ} \mathrm{C}$. Tests for metronidazole and clarithromycin sensitivity were then done using an in vitro disk method (Mast sensitivity disks ( $5 \mu \mathrm{g}$ ), Mast Laboratories, Liverpool; Sensi disks (1 $\mu \mathrm{g})$, Beckton Dickenson Microbiological Systems, Cockeysville, MD, USA).

Patients were classified as $H$ pylori positive by a positive ${ }^{13} \mathrm{C}$-UBT and positive histoligical tests or culture. Clearance of $H$ pylori was defined as a negative ${ }^{13} \mathrm{C}$-UBT (excess $\delta^{13} \mathrm{CO}_{2}$ excretion $<5$ per mil) at the end of treatment, while eradication was defined as a negative ${ }^{13} \mathrm{C}$-UBT one month or longer after the end of treatment.

\section{${ }^{13}$ C-UREA BREATH TEST}

The ${ }^{13}$ C-UBT (European Standard Protocol) ${ }^{12}$ was done within two days of the initial endoscopy in all patients. Briefly, a baseline sample of expired breath was collected before drinking a fatty liquid test meal (76\% lipid, 19\% carbohydrate, $5 \%$ protein) to delay gastric emptying. After 10 minutes, ${ }^{13} \mathrm{C}$-urea $100 \mathrm{mg}(99 \%$ pure, Cambridge Isotopes, Boston, Mass) in $50 \mathrm{ml}$ of tap water was swallowed and distributed within the stomach by turning the patient to the left and right decubitus position. Two litre serial breath samples were collected every five minutes into a large reservoir collecting bag, from which a single $20 \mathrm{ml}$ aliquot was taken at the end of the test and analysed by mass spectrometry (Bureau of Stable Isotope Analysis, Brentford, London). A positive result was defined as excess $\delta^{13} \mathrm{CO}_{2}$ excretion $>5$ per mil, as determined from previous studies. ${ }^{12}$

\section{TREATMENT}

Patients with a positive ${ }^{13} \mathrm{C}$-UBT, and positive histological tests or positive culture, or both, were given omeprazole $40 \mathrm{mg}$ each morning and clarithromycin $500 \mathrm{mg}$ thrice daily for 14 days. Patients were forewarned of possible taste disturbance. The dose and frequency of the regimen was based on the half life of clarithromycin and facilitating patient compliance.

\section{FOLLOW UP}

A second ${ }^{13} \mathrm{C}$-UBT was done immediately after completing treatment, when compliance and side effects were assessed by returned tablet count and direct questioning. A third ${ }^{13} \mathrm{C}$-UBT was done one month later, with a negative result taken to point to successful eradication. In patients in whom $H$ pylori was not eradicated, repeat endoscopy with biopsy specimens and cultures were done to determine if treatment failure was a result of the development of clarithromycin resistance.

\section{Results}

Seventy three patients ( 36 men, median age 46 years, range $29-68$, with either active or previous duodenal ulcers $(n=42)$ or dyspepsia with endoscopic duodenitis/non-ulcer dyspepsia $(n=31)$ ) all with a positive ${ }^{13} \mathrm{C}$-UBT (mean (SEM) excess $\delta^{13} \mathrm{CO}_{2}$ excretion $=26 \cdot 6(4 \cdot 9)$ per mil) and either positive antral histology $(n=72)$ or positive antral culture $(n=35)$ were studied. Twenty five (34\%) patients had previously received anti$H$ pylori treatment ${ }^{313}$ but had failed to eradicate the infection.

In $70 / 73(96 \%)$ the ${ }^{13} \mathrm{C}$-UBT was negative immediately after finishing treatment. Four weeks after the end of treatment the ${ }^{13} \mathrm{C}$-UBT was negative in 57/73 (mean (SEM) excess $\delta^{13} \mathrm{CO}_{2}$ excretion $=1 \cdot 2(0 \cdot 3)$ per mil) eradication rate $=78 \%$, intention to treat analysis, Figure). $H$ pylori was not eradicated in 16 patients, including one patient who took the drugs for only three days. In those patients in whom $H$ pylori had failed previous treatments $(\mathrm{n}=25)$, eradication was achieved in 16/25 (64\%) compared with $41 / 48(85 \%)$ of those who had not been previously treated $\left(\chi^{2}=4 \cdot 4, p=0 \cdot 04\right)$.

Forty eight patients $(48 / 73,66 \%)$ experienced a dry metallic taste while taking the tablets, which prevented three patients from completing the course of treatment; in one patient severe taste disturbance occurred within three days of starting treatment. In the remaining patients taste disturbance resolved completely within days of finishing treatment and did not impair compliance or eradication. Other side effects occurred infrequently (7\%) and included nausea, headache, and oral candidiasis. No patient experienced diarrhoea.

\section{ANTIBIOTIC SENSITIVITIES}

Before treatment positive cultures were obtained from 35/51 patients studied. Of 27 available isolates, $25 / 27$ (93\%) were sensitive to clarithromycin while in five patients isolates of $H$ pylori were resistant to metronidazole. $H$ pylori was eradicated in both patients with pretreatment clarithromycin resistant strains and in $4 / 5$ patients with metronidazole resistant strains.

Comparison of before and after treatment isolates from $8 / 16$ available culture showed acquired clarithromycin resistance in one of five patients with persistent $H$ pylori. $H$ pylori could not be adequately cultured in three further patients who failed treatment.

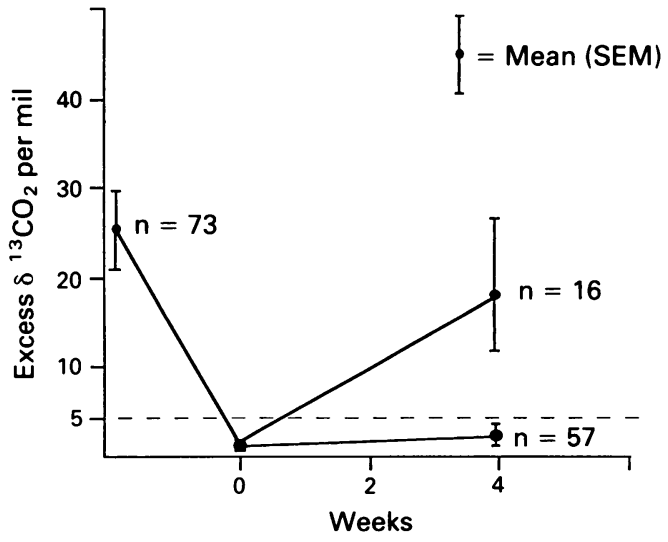

${ }^{13} \mathrm{C}$-urea breath test results showing the effect of two weeks clarithromycin $500 \mathrm{mg}$ thrice daily and omeprazole $40 \mathrm{mg}$ in the morning, before and at 0 and four weeks after finishing treatment (=eradication). (Positive result $=$ excess $\delta^{13} \mathrm{CO}_{2}$ excretion $>5$ per mil. $)$ 


\section{Discussion}

This new combination of the powerful acid inhibitor omeprazole and an antibiotic (dual therapy) has both theoretical and practical advantages over standard triple therapy for eradicating $H$ pylori. It is a logical, rational first line 'curative' treatment of duodenal ulcer with excellent compliance because it is well tolerated and uses less than half the tablets of two weeks triple therapy. Our results suggest that the new dual therapy using omeprazole and clarithromycin may be an effective alternative to triple therapy for eradicating $H$ pylori.

The in vitro activity of erythromycin against $H$ pylori is comparable with other antibiotics, but its prokinetic activity (causing side effects) and poor acid stability have limited its use in the treatment of $H$ pylori. The newer macrolide antibiotics were designed to overcome the parent compound's drawbacks and are active in vitro against $H$ pylori, but only clarithromycin is also active in vivo. Indeed results to date suggest that clarithromycin is the most effective anti- $H$ pylori drug available at present. ${ }^{14}$ is In a preliminary study of single drug therapy Graham found clarithromycin $250 \mathrm{mg}$ four times daily for two weeks eradicated $H$ pylori in 6/14 (42\%) subjects, ${ }^{14}$ while Neri et al found that clarithromycin (250 mg four times daily) combined with colloidal bismuth subcitrate $(120 \mathrm{mg}$ four times daily) for two weeks increased the eradication rate to $52 \% .^{16}$ The high eradication rate achieved in our study by clarithromycin with omperazole is probably because of the lower $\mathrm{MIC}_{90}$ of clarithromycin and its active 14-hydroxy metabolite at the higher $\mathrm{pH}$ produced by omeprazole. The intrinsic $H$ pylori suppressive properties of omeprazole, however, may also have been important. ${ }^{17-19}$ Primary and acquired resistance to macrolides is a recognised problem and may also occur with clarithromycin, making further studies of treatment with clarithromycin alone unlikely.

Similar encouraging results to our own have been reported with omeprazole and amoxycillin duel therapy. ${ }^{20}$ Several groups have failed, however, to duplicate the initial encouraging results; our results show an eradication rate of $28 \%$ with variable results $(43 \%-0 \%)$ reported by others. ${ }^{21-24}$ Unge et al using omeprazole $40 \mathrm{mg}$ in the morning and amoxycillin $750 \mathrm{mg}$ twice daily found an overall eradication rate of $54 \%$ although in compliant patients $(<33 \%$ of study population) the eradication rate was $74 \% .{ }^{24}$

The eradication rate of the omeprazole and clarithromycin dual therapy recorded in this study compares favourably with that of standard triple therapy. Although the eradication rate was lower in patients previously treated for $H$ pylori, this did not seem to be because of differences in patient compliance or antimicrobial sensitivity and was not seen in previous studies. ${ }^{3}{ }^{132}$

At the comparatively high doses, similar to those used in this study, clarithromycin may cause a metallic taste (manufacturer's data). Patients were therefore warned of this before starting treatment and although $66 \%$ had a transient taste disturbance, over $95 \%$ could complete the regimen successfully and eradicate $H$ pylori. Only one patient had this side effect immediately and intolerably, possibly an idiosyncratic response, but the importance of taste disturbance varies between different people and ethnic groups.

In this study $93 \%$ of the strains of $H$ pylori studied were initially sensitive to clarithromycin, but in one of the five patients in whom treatment failed the bacteria had become resistant to clarithromycin. Resistance to clarithromycin may arise less readily than to imidazoles, ${ }^{25}$ but more data are needed to quantify this problem and suggest preventative methods. Further studies are also needed to optimise the dose and duration of clarithromycin and an appropriate antisecretagogue.

In clinical practice this dual therapy of omeprazole and clarithromycin may provide an effective alternative first line anti- $H$ pylori treatment in populations where the prevalence of imidazole resistant $H$ pylori is high. We currently use this regimen as first line treatment for patients with known metronidazole resistant $H$ pylori and as second line treatment after failure of standard triple therapy.

Preliminary results of this study were presented as an abstract to the British Society of Gastroenterology in September 1992. The authors thank the medical and endoscopy staff of both Hospitals for their help and cooperation, and Abbott Laboratories for their support.

1 Rauws EAJ, Tytgat GNJ. Cure of duodenal ulcer with eradication of Helicobacter pylori. Lancet 1990; 335: 1233-5.

2 Tytgat GNJ, Axon ATR, Dixon MF, Graham DY, Lee A, Marshall BJ, et al. Helicobacter pylori: causal agent in peptic ulcer disease? World Congress of Gastroenterology Working Party Report. Oxford: Blackwell Scientific, 1990: 36-45.

3 Logan RPH, Gummett PA, Misiewicz JJ, Karim QN, Walker $\mathrm{MM}$, Baron $\mathrm{JH}$. A one week eradication regime for Helicobacter pylori. Lancet 1991; 338: 1249-52.

4 Glupczynski Y, Burette A, De Koster E, Nyst J-F, Deltenre $M$, Cadranel S, et al. Metronidazole resistance in Helicobacter pylori [Letter]. Lancet 1990; 335: 976-7.

5 Graham DY, Lew GM, Malaty HM, et al. Factors influencing the eradication of helicobacter pylori with triple therapy. Gastroenterology 1992; 102: 493-6.

6 Weil J, Bell DG, Powell K, et al. Omeprazole and Helicobacter pylori: temporary suppression rather than true eradication. Aliment Pharmacol Therap 1991; 5: 309-13.

7 Sharp J, Logan RPH, Walker MM, Gummett PA, Missiewicz JJ, Baron JH. Effect of omeprazole on Helicobacter pylori. Gut 1991; 32: A565.

8 Stolte M, Bethke B. Elimination of helicobacter pylori under treatment with omeprazole. Z Gastroenterol 1990; 28: 271-4.

9 Westblom TU, Duriex D. Enhancement of antibiotic concentrations in gastric mucosa by $\mathrm{H}_{2}$ antagonist. Dig $\mathrm{Dis} S \mathrm{Si}$ 1991; 36: 25-8.

10 Clarithromycin and azithromycin - better erythromycins? Drug Ther Bull 1991; 29: 26.

11 Weller IVD, Williams CB, Jeffries DJ, Leicester RJ, Gazzard BG, Axon ATR, et al. Cleaning and disinfection of equipment for gastrointestinal flexible endoscopy: interim recommendations of a Working Party of the British Society of Gastroenterology. Gut 1988; 29: 1134-51.

12 Logan RPH, Dill S, Bauer FE, et al. The European ${ }^{13} \mathrm{C}$-Urea Breath Test for the detection of Helicobacter pylori. Eur $\mathcal{F}$ Gastroenterol Hepatol 1991; 3: 915-21.

13 Logan RPH, Gummett PA, Misiewicz JJ, Karim QN, Walker MM, Baron JH. Two week eradication regimen for metronidazole resistant Helicobacter pylori. Aliment Pharmacol Therap 1993; 7: 149-53.

14 Graham DY, Operkun AR, Klein PD. Clarithromycin for the eradication of Helicobacter pylori. F Clin Gastroenterol 1993; 16: $292-4$.

15 Logan RPH, Gummett PA, Hegarty BT, Walker MM, Baron JH, Misiewicz JJ. Clarithromycin and omeprazole for JH, Misiewicz JJ. Clarithromycin and

16 Neri M, Susi D, Bovani I, Pindo R, Cuccurullo F. Omeprazole, bismuth and clarithromycin: a new strategy for the treatment of Helicobacter pylori (HP) related gastritis. Ir f Med Sci 1992; 161 (suppl 10): 3.

17 Logan RPH, Gummett PA, Walker MM, Polson RJ, Baron JH, Misiewicz JJ. Does omeprazole (OME) affect Helicobacter pylori infection. Eur $\mathcal{F}$ Gastroenterol Hepatol 1991; 3 (suppl 1): S10.

18 Hui WM, Lam SK, Ho J, et al. Effect of omeprazole on duodenal ulcer-associated antral gastritis and Helicobacter pylori. Dig Dis Sci 1991; 36: 577-82.

19 Daw MA, Deegan P, O'Morain C. The effect of omeprazole on Helicobacter pylori and associated gastritis. Aliment Pharmacol Therap 1991; 5: 435-9. 
20 Labenz J, Gyenes E, Rhul GH, Borsch G. Amoxycillinomeprazole treatment for eradication of Helicobacter pylori. Eur $\mathcal{f}$ Gastroenterol Hepatol 1991; 3 (suppl 1): S10.

21 Logan RPH, Rubio MA, Gummett PA, Hegarty B, Walker $M M$, Baron $\mathrm{JH}$, et al. Omperazole and amoxycillin suspension for Helicobacter pylori. Ir f Med Sci 1992; 161 (supp 10): 16

22 Bell DG, Powell K, Weil J, et al. Experience with omeprazole in combination with either amoxycillin or colloidal bismuth subcitre in patients with metronidazole-risth Helicobacter pylori. Eur f Gastroenterol Hepatol 1991; 3: Helico 923 .
23 De Koster E, Nyst JF, Deprez C, Glupczynski Y, Jonas C, Denis $\mathrm{P}$, et al. $\mathrm{Hp}$ treatment: disappointing results with amoxicillin plus omeprazole. Ital $\mathcal{f}$ Gastroenterol 1991; 23 (suppl 2): 105

24 Unge P, Eriksson K, Bergman B, et al. Omeprazole and amoxycillin in patients with duodenal ulcer: Helicobacter pylori eradication and remission of ulcers and symptoms during a 6 month follow-up. Gastroenterology 1992; 102: A183.

25 Marshall BJ, Goodwin CS, Warren JR, Murray R, Blincow Wective double-blind trial of pylori. Lancet 1988; ii: 1437-42. 